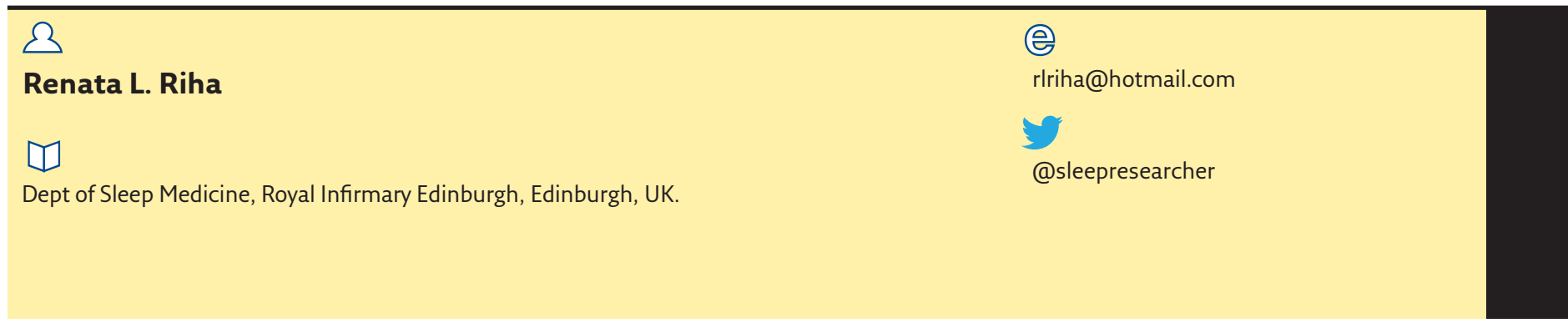

\title{
Breathe: exploring local and global issues in respiratory health
}

Welcome to the September issue of Breathe! In this edition we explore some local and global issues in respiratory health, focusing on spirometry, bronchiectasis, obstructive sleep apnoea and air pollution. We also have several contributions from junior members about their training and on-call experiences in different countries. We have a fascinating report by a courageous respiratory nursing colleague who used her skills to assist with a research project in Africa during the Ebola crisis [1]. Her account demonstrates that our training can be used in many fields of endeavour.

The excellent contributions in this issue provide practical insights and tips on dealing with some of the most common illnesses and procedures we confront in our local hospitals and may also give us pause to consider how we adapt to the particular conditions in which we practise.

The issue of air pollution, both indoor and outdoor, highlights one of the most ubiquitous precipitants of lung disease worldwide. Having recently spent time in Mongolia, I was struck by the contrast between Ulaanbaatar, the second most polluted city in the world (figure 1), with the wide open steppes where the nomads pitch their gers. The nomads themselves minimise indoor air pollution by traditionally placing their stoves with the chimney in the centre of the ger so that any smoke escapes outside the dwelling (figure 2). Air pollution should be a matter of concern not just for individual practising physicians but for society as a whole, touching on all aspects of town planning, legislation to deal with noxious by-products of industry, car fumes and the long-term use of fossil fuels. This issue includes an editorial from the European Lung Foundation focusing on how to explain the risk of air pollution to patients [2].

Additional features will be made available as online exclusives, so please, make sure you come back to us to read and share this material (breathe.ersjournals.com). One of these articles provides useful guidance on how to prepare for what can be the most daunting day of your life, the job interview. Another focuses on the experience of sleep physicians in the UK with early adoption of European Union Directive 2014/85/ EU concerning driver licensing in obstructive sleep apnoea.

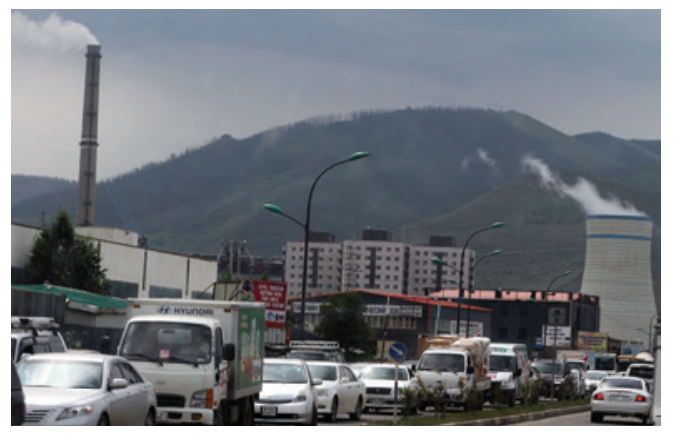

Figure 1 Air pollution in Ulaanbaatar in summer.
Cite as: Riha RL. Breathe: exploring local and global issues in respiratory health. Breathe 2016; 12: 199-200. 


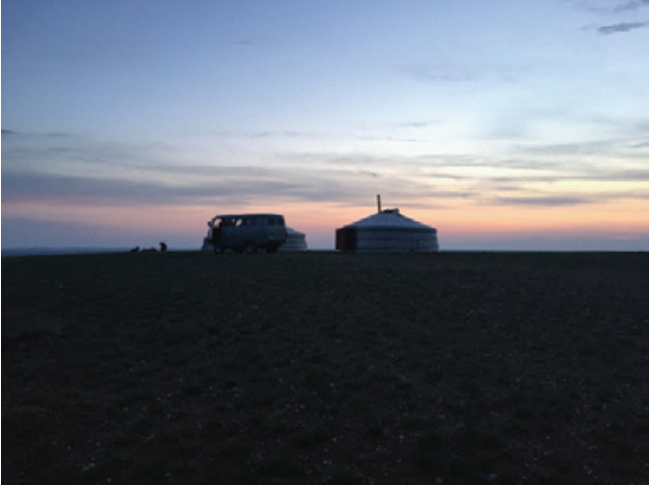

Figure 2 Ger on the Mongolian steppe. Image courtesy of Tomas A. Ray.
A new development for Breathe is the establishment of an online journal club, coordinated by Frits Franssen (secretary of group 01.02: Rehabilitation and Chronic Care). The first journal club will tie in with the focus of the December issue around respiratory health and disability. This will become a regular feature and we hope to work with the Education Council and the Society as a whole to ensure this initiative has a broad scope. We hope you will be able to participate. Watch this space for more details!

Finally, my thanks goes to all contributors to this issue who have given their time and shared their personal experiences with the readership at large, as well as the editorial team. I hope to see you at the ERS International Congress!

\section{Conflict of interest}

None declared.

\section{References}

1. Ferguson $\mathrm{S}$. The challenges of research nursing in an outbreak setting. Breathe 2016; 12: 209-211.
2. Powell P, Brunekreef B, Grigg J. How do you explain the risk of air pollution to your patients? Breathe 2016; 12: 201-203. 